\title{
Dual Band Switchable Voltage Controlled Oscillator in 65-nm CMOS Technology
}

\author{
${ }^{\mathrm{a}}$ Waseem Abbas, ${ }^{\mathrm{b}}$ Hamayoun Shahwani, ${ }^{\mathrm{c}}$ Muhammad Ashraf, ${ }^{\mathrm{d}}$ Muhammad Akram, ${ }^{\mathrm{e} J a w a d}$ Yousaf, \\ ${ }^{a}$ Zubair Mehmood and ${ }^{\mathrm{a}}$ Amir Altaf \\ a: Department of Electrical and Computer Engineering, Sungkyunkwan University, South Korea \\ b: Department of Telecommunication Engineering, c: Department of Computer Engineering, \\ d: Department of Software Engineering, Faculty of Information and Communication Technology, \\ BUITEMS, Pakistan \\ e: Department of Electrical and Computer Engineering, Abu Dhabi University, Abu Dhabi
}

\begin{abstract}
A switchable differential voltage-controlled oscillator (VCO) has been fabricated in 65nm CMOS. It is a dual frequency VCO whose oscillation frequencies can be changed from $40 \mathrm{GHz}$ (VCO1) to $80 \mathrm{GHz}$ (VCO2). The tuning range for VCO1 is $1 \mathrm{GHz}$ and for VCO2 is 4GHz. The inductor switching is attained with the help of transistor as a switch and inductors are fabricated in a stacked manner for saving die area. The output power of VCO1 is $1 \mathrm{dBm}$ and for VCO2 is $0 \mathrm{dBm}$ with a total power consumption of $42 \mathrm{~mW}$. The phase noises were $-\mathbf{9 4 . 6 2} \mathrm{dBc} / \mathrm{Hz}$ and $-81.43 \mathrm{dBc} / \mathrm{Hz}$ at $1 \mathrm{MHz}$ offset for VCO1 and VCO2 respectively. The chip area is $500 \mathrm{x} 560 \mathrm{um}{ }^{2}$ including probing pads.
\end{abstract}

Keywords- Switchable, voltage-controlled oscillator (VCO), CMOS, phase noise

Date Received 09 Dec 2019

Date Accepted 01 Apr 2020

Date Published 25 June 2020

\section{INTRODUCTION}

$\mathrm{T}$ HE signal sources play a vital role in either analog or digital SIGNAL systems. In recent studies, the PLLs for $\mathrm{W}$ and D band have been realized in $65 \mathrm{~nm}$ and $0.13 \mathrm{um}$ [1,2]. For $\mathrm{V}$ and $\mathrm{W}$ band, no such type of VCOs is observed. In designing of VCO normally two approaches are used one is fundamental oscillator and other one is harmonic oscillator either $2^{\text {nd }}$ harmonic or higher order. After designing the oscillator there are many factors that affect the performance of an oscillator like phase noise, low output power and spurs [3,4]. The circuit components other than transistors are also contributing for performance degradation. Due to low quality factor of varactors the oscillation frequency decreases from estimated theoretical value. The quality factor of inductor and line losses are also degrading the performance of an oscillator not only in terms of frequency but also in terms of output power. The process variations and temperature are also the parameters who add alterations in the circuit performance [5]. More than $100 \mathrm{GHz}$ oscillation frequency has been achieved already in several VCOs with variety of circuit topologies.

In this paper, we proposed a cross coupled differential VCO with no capacitor for frequency tuning. The transistors are being used as a varactor for tuning output frequency in this VCO. This is dual band VCO for W and D band.

This work is arranged as follows. The circuit description of proposed VCO is illustrated in Section II. Section III

Journal of Applied and Emerging Sciences Vol (10), Issue (01) summarizes the experimental results of the proposed work.

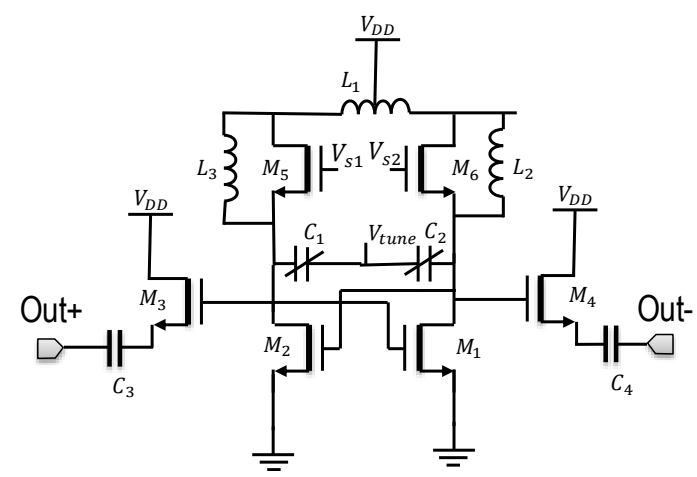

Fig. 1. Schematic of proposed dual band switchable VCO

Finally, Section IV includes the conclusion of this work.

\section{CIRCUIT DESCRIPTION}

Fig. 1 shows the schematic of proposed VCO. The cross coupled technique is used for base oscillator.

\section{A. Methodology}

The cross coupled oscillator working principle is stated that the real part of oscillator core circuit's impedance or negative transconductance $\left(\mathrm{g}_{\mathrm{m}}\right)$ of the transistor must be higher enough for both frequencies (for dual oscillator) to compensate the real part of impedance or loss of the resonator to meet the $1^{\text {st }}$ oscillation condition. The imaginary part of the impedance of core circuit should be equal and negative to the imaginary part of the resonator for $2^{\text {nd }}$ condition meet up. 
The required minimum transconductance is given as:

$$
g_{m}=\frac{1}{R_{p}}
$$

Where $R_{p}$ is the loss of the resonator and $g_{m}$ is the transconductance of the core circuit [6].

The oscillation frequency of the oscillator can be estimated from the below mentioned expression:

$$
\omega_{o s c} \approx \frac{1}{\sqrt{L_{1}+L_{2}+L_{3}\left(C_{1}+C_{2}\right)}}
$$

The $M_{1}$ and $M_{2}$ with gate width of 36 um are used for core circuit. The $\omega_{o s c}$ will vary due to change in inductor values which depends on the switch selection either for $40 \mathrm{GHz}$ or for $80 \mathrm{GHz}$.

\section{B. Circuit Design}

The transistors with shorted drain and source are used as varactors whose labels are $C_{1}$ and $C_{2}$ with 20 um gate width. The $M_{3}$ and $M_{4}$ are worked as source follower for output termination. The gate width for source follower transistors is 20 um. The output capacitors $\mathrm{C}_{3}$ and $\mathrm{C}_{4}$ with source follower are having value of $800 \mathrm{fF}$ with metal insulated metal (MIM) design configuration. These capacitors are designed with OA top metal layer which is less lossy as compare to other metal layers. The capacitance value of different widths of transistor with respect to tuning voltage is depicted in Fig. 2. Fig. 3 shows quality factor of varactors with respect to tuning voltage. This is the reason for selection of $20 \mathrm{um}$ gate width for wider tuning range.

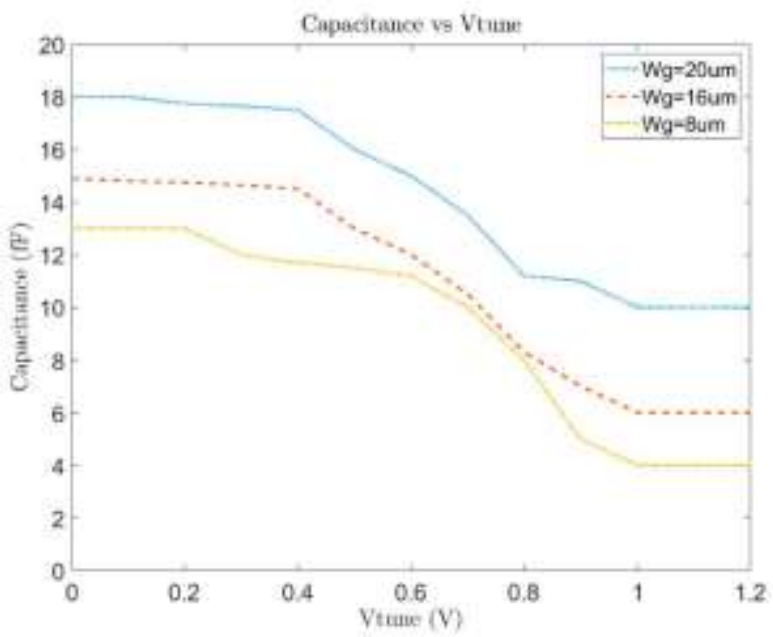

Fig. 2. Variation of different gate width capacitances w.r.t tuning voltage

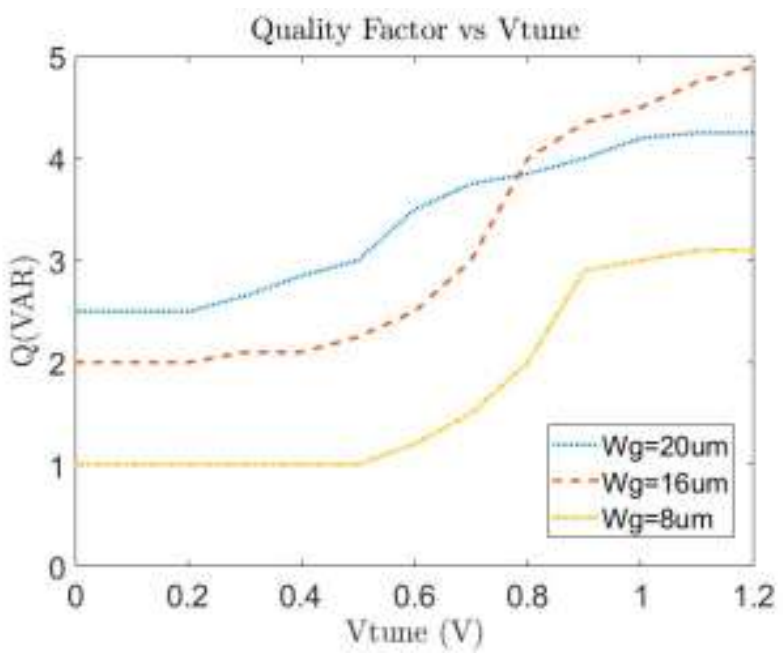

Fig. 3. Varactors quality factor w.r.t tuning voltage variation

The core circuit is leading the switching circuit which is used for inductor switching. The $1^{\text {st }}$ switch $\mathrm{V}_{\mathrm{sw} 1}$ is used for small oscillator with large inductor whose output frequency is $40 \mathrm{GHz}$ and $2^{\text {nd }}$ switch $\mathrm{V}_{\mathrm{sw} 2}$ is utilizes the small inductor for high frequency oscillation with $80 \mathrm{GHz}$ output. The $\mathrm{M}_{5}$ and $\mathrm{M}_{6}$ are used with gate width 20 um for switching purpose.

The $\mathrm{L}_{1}$, center tapped inductor is designed separately with inductance of $40 \mathrm{pH}$ and it is utilized in both VCO modes. The $\mathrm{L}_{2}$ and $\mathrm{L}_{3}$ are designed in stacked fashion for saving die area with values of $20 \mathrm{pH}$ and $70 \mathrm{pH}$ respectively.

The micro-photograph of the dual band $\mathrm{VCO}$ with probing pads is portrayed in Fig. 4 with a die area of $500 \times 560 \mathrm{um}^{2}$.

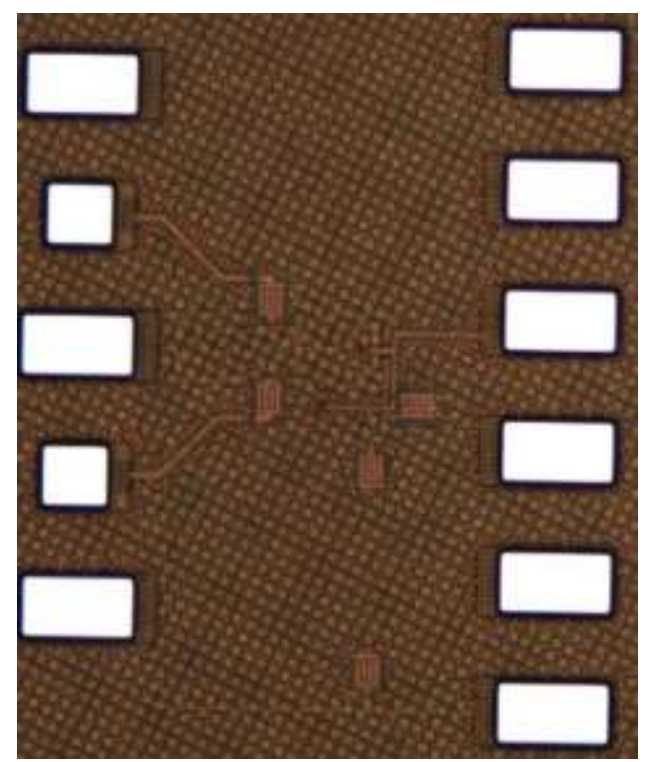

Fig. 4. chip microphotograph of proposed dual band VCO

\section{EXPERIMENTAL RESULTS}

The proposed VCO is simulated with EM momentum setup in ADS design tool. The schematic is designed in Spectre (Cadence) with $65 \mathrm{~nm}$ CMOS process design kit. The two different oscillation frequencies are observed with switched VCO characteristics. $80 \mathrm{GHz}$ with output power of $0 \mathrm{dBm}$ is 
achieved with switch 1 and inductor $\mathrm{L}_{2}$, sensitivity of $\mathrm{VCO}$ w.r.t time is shown in Fig. 4 with a tuning range of $4 \mathrm{GHz}$.

Table 1: Performance Comparison with Prior Dual Band VCOs

\begin{tabular}{|l|l|l|l|l|}
\hline Ref \# & {$[10]$} & {$[11]$} & {$[12]$} & This work \\
\hline $\begin{array}{l}\text { Freq } \\
(\mathrm{GHz})\end{array}$ & $45 / 60$ & $24 / 60$ & $38 / 19$ & $40 / 80$ \\
\hline Tech. & $\begin{array}{l}0.25 \mathrm{um} \\
\text { BiCMOS }\end{array}$ & $\begin{array}{l}0.13 \mathrm{um} \\
\text { CMOS }\end{array}$ & $\begin{array}{l}0.25 \mathrm{um} \\
\text { BiCMOS }\end{array}$ & $\begin{array}{l}65 \mathrm{~nm} \\
\text { CMOS }\end{array}$ \\
\hline $\begin{array}{l}\text { PN@1M } \\
(\mathrm{dBc} / \mathrm{Hz})\end{array}$ & $\begin{array}{l}-99 /-93 \\
(@ 10 \mathrm{M})\end{array}$ & $\begin{array}{l}-120 /-114 \\
(@ 10 \mathrm{M})\end{array}$ & $-106.8 /-112$ & $-94 /-81$ \\
\hline Pdc (mW) & $32.5 / 17.5$ & $24 / 11$ & $105.6 / 69.3$ & 42 \\
\hline FOMPN & $158 / 156$ & $177 / 176$ & $178 / 180$ & $170 / 163$ \\
\hline \multicolumn{5}{|c|}{$F O M_{P N}=-L(\Delta f)+20 \log \frac{f_{\text {osc }}}{\Delta f}-10 \log \frac{P_{d c}}{1 m W}$} \\
\hline
\end{tabular}

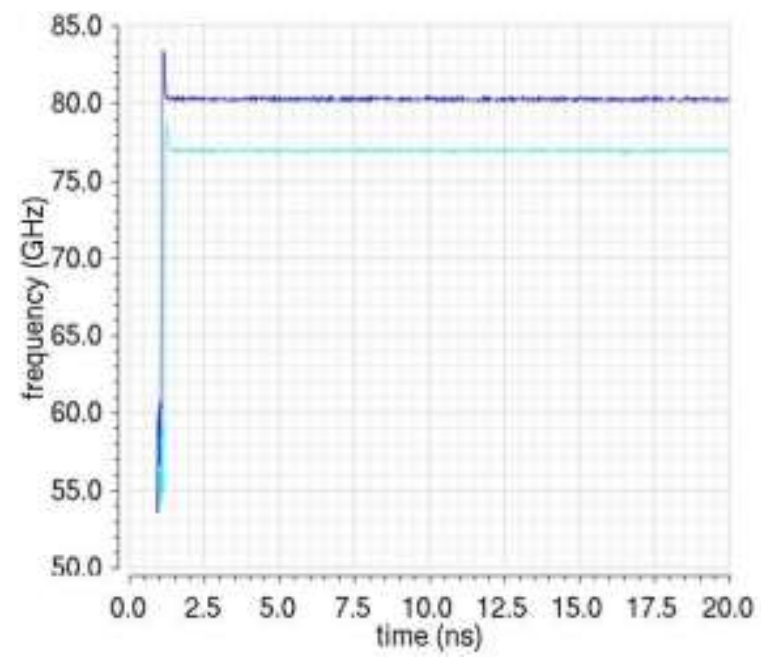

Fig. 4. Output Frequency sensitivity w.r.t time for $80 \mathrm{GHz}$ VCO

Similarly, $40 \mathrm{GHz}$ can be obtained with switch 2 and inductor $\mathrm{L}_{1}$ as described in Fig. 5. The tuning range for $40 \mathrm{GHz}$ is $1 \mathrm{GHz}$ and it can also be observed in Fig. 5.

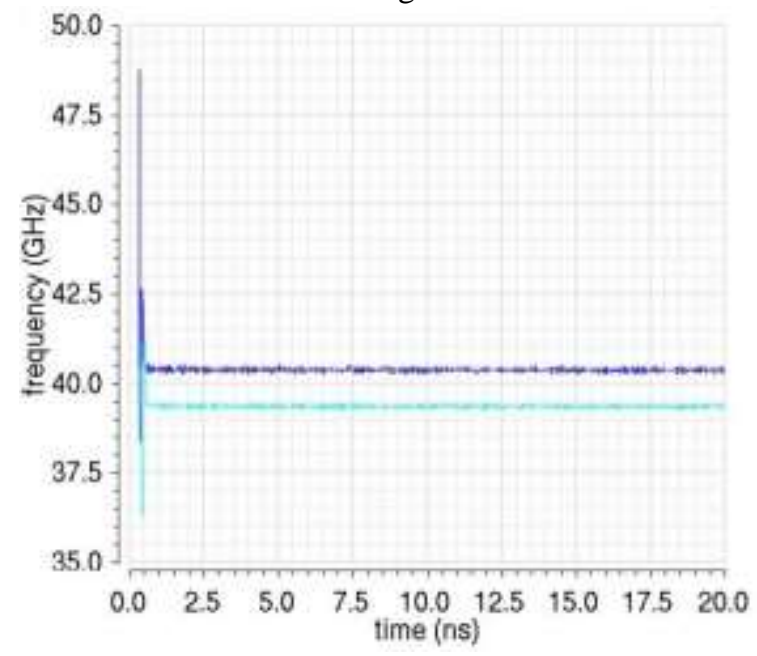

Journal of Applied and Emerging Sciences Vol (10), Issue (01)
Fig. 5. Output Frequency sensitivity w.r.t time for $40 \mathrm{GHz}$ VCO



Fig. 6. Frequency spectrum for both $\mathrm{VCO}_{1}$ and $\mathrm{VCO}_{2}$


Fig. 7. Tuning range for both $\mathrm{VCO}_{1}$ and $\mathrm{VCO}_{2}$ w.r.t tuning voltages 
Fig. 8. Output power for both $\mathrm{VCO}_{1}$ and $\mathrm{VCO}_{2}$ w.r.t tuning voltages

The frequency spectrum for both VCO modes can be seen in Fig. 6 and it is also verifying the results of Fig. 4 and Fig. 5.

The tuning range of output frequency and output power of output signal are also plotted w.r.t tuning voltage in Fig. 7 and Fig. 8 respectively.

The phase noise is the most important parameter of an oscillator and it is necessary to illustrate phase noise for both modes of $\mathrm{VCO}$ and it is shown in Fig. 9 with reasonable phase noise of $94.62 \mathrm{dBc} / \mathrm{Hz}$ and $-81.43 \mathrm{dBc} / \mathrm{Hz}$ at $1 \mathrm{MHz}$ offset for $\mathrm{VCO}_{1}$ and $\mathrm{VCO}_{2}$ respectively.

Table 1 compares the performance with state-of-the-art dual band VCOs. For comparison, the figure of merit considering phase noise $\left(\mathrm{FOM}_{\mathrm{PN}}\right)$ is used. The proposed VCO achieves superior FOM $_{\mathrm{PN}}$

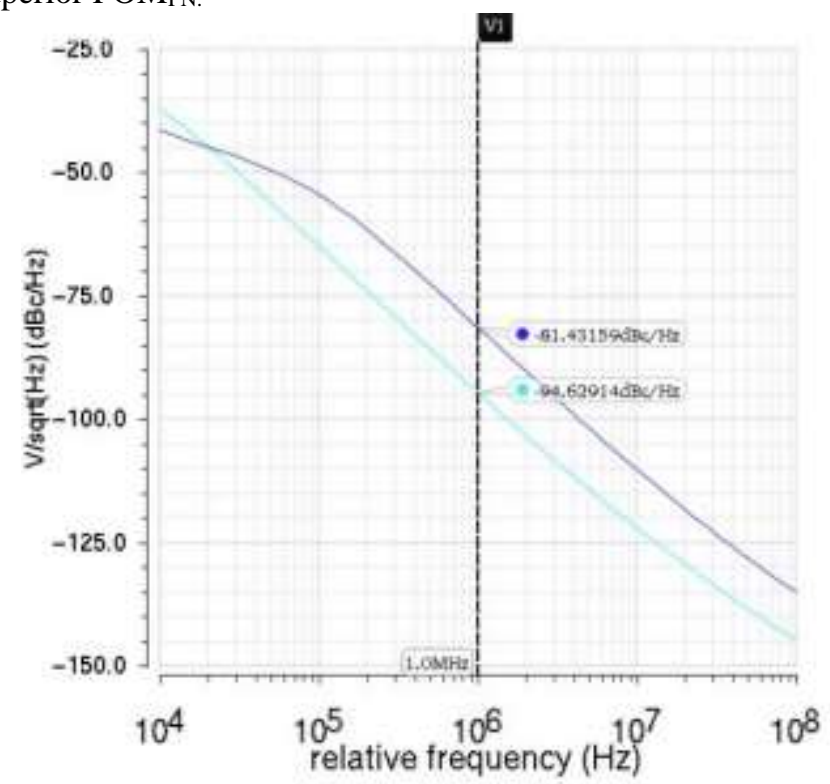

Fig. 9. Phase noise for both $\mathrm{VCO}_{1}$ and $\mathrm{VCO}_{2}$ at offset of $1 \mathrm{MHz}$

\section{CONCLUSION}

The implemented dual band VCO has been presented with 40 $\mathrm{GHz}$ and $80 \mathrm{GHz}$ output frequencies. Inductor switching using transistor and transistor-based varactors are implemented in this work. The low power consumption with 0 to $1 \mathrm{dBm}$ output power is observed for both modes of VCO.

\section{REFERENCES}

[1] M. Tanomura, Y. Hamada, S. Kishimoto, M. Ito, N. Orihashi, K. Maruhashi, and H. Shimawaki, "TX and RX front-ends for $60 \mathrm{GHz}$ band in $90 \mathrm{~nm}$ standard bulk CMOS," in IEEE Int. Solid-State Circuits Conf. Dig. Tech. Papers, Feb. 2008, pp. 558-559.

[2] S. T. Nicolson, P. Chevalier, B. Sautreuil, and S. P. Voinigescu, "Single-chipW-band SiGe HBT transceivers and receivers for doppler radar and millimeter-wave imaging," IEEE J. Solid-State Circuits, vol. 43, pp. 2206-2217, 2008.

[3] K. Scheir, G. Vandersteen, Y. Rolain, and P. Wambacq, "A 57-to-66 $\mathrm{GHz}$ quadrature PLL in $45 \mathrm{~nm}$ digital CMOS," in IEEE Int. Solid-State Circuits Conf. Dig. Tech. Papers, Feb. 2009, pp. 494-495 and 495a.

[4] J. Grzyb, Y. Zhao, and U. R. Pfeiffer, "A 288-GHz lens-integrated balanced triple-push source in a 65-nm CMOS technology," IEEE J. Solid-State Circuits, vol. 48, no. 7, pp. 1751-1761, Jul. 2013.

Journal of Applied and Emerging Sciences Vol (10), Issue (01)
[5] S. Shahramian et al., "Design of a dual W- and D-band PLL," IEEE J. Solid-State Circuits, vol. 46, no. 5, pp. 1011-1022, May 2011.

[6] K.-H. Tsai, L.-C. Cho, J.-H. Wu, and S.-I. Liu, "3.5 mW W-band frequency divider with wide locking range in $90 \mathrm{~nm}$ CMOS technology," in Proc. IEEE Int. Solid-State Circuits Conf., Feb. 2008, pp. 466-467.

[7] K. W. Tang, S. Leung, N. Tieu, P. Schvan, and S. P. Voinigescu, "Frequency scaling and topology comparison of millimeter-wave CMOS VCOs," in Proc. IEEE Compound Semiconductor Integr. Circuit Symp., Nov. 2006, pp. 55-58.

[8] S. Kang and A. M. Niknejad, "A $100 \mathrm{GHz}$ active-varactor VCO and a bidirectionally injection-locked loop in 65nm CMOS," in Proc. IEEE Radio Freq. Integr. Circuits (RFIC) Symp., pp. 231 - 234, Jun. 2013.

[9] J. Yin and H.C. Luong, "A 57.5-90.1-GHz Magnetically Tuned Multimode CMOS VCO,” IEEE J. Solid-State Circuits, vol.48, no.8, pp.1851-1861, Aug. 2013.

[10] J.-Y. Lee, S.-H. Lee, H. Kim and H.-K. Yu, "A 45-to-60 GHz two-band $\mathrm{SiGe}$ C VCO for millimeter-wave applications," in IEEE RFIC Symp., Jun. 2007, pp.709-712.

[11] L. Wu, A. W. L. Ng, L. L. K. Leung and H. C. Luong, "A 24- GHz and $60 \mathrm{GHz}$ Dual-band Standing-wave VCO in 0.13- um CMOS process," in IEEE RFIC Symp., Jun. 2010, pp. 145-148.

[12] Y. Chen, Y. Pei and D. W. Leenaerts, "A Dual-band LO Generation System using a $40 \mathrm{GHz}$ VCO with a Phase Noise of $-106.8 \mathrm{dBc} / \mathrm{Hz}$ at $1-$ MHz,” in IEEE RFIC Symp., 2013, pp.203-206.

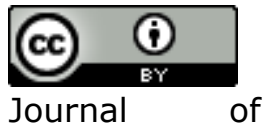

Applied and

Emerging Sciences by BUITEMS is licensed under a Creative Commons Attribution 4.0 International License. 